\title{
Spirituality and Mental Well Being in Old Age
}

$$
\text { John Wattis }{ }^{1} \text {, Stephen Curran², }
$$

${ }^{1}$ University of Huddersfield

2 University of Huddersfield and South West Yorkshire Mental Health NHS Trust 


\title{
Spirituality and Mental Well Being in Old Age
}

\author{
John Wattis \& Stephen Curran
}

\begin{abstract}
This article reflects on the difficult relations between science and religion, the role of spiritual belief in the mental health of the elderly patient and the evidence it has an effect even on patients with dementia.
\end{abstract}

Key words: spirituality, mental well being, old age.

\begin{abstract}
'If the head and body are to be well, you must first begin by curing the soul, that is the first thing ...... the great error of our day is that physicians separate the soul and the body, when they treat the body.' - Plato' (Koenig 1994)
\end{abstract}

The divorce between science and religion that started with the $18^{\text {th }}$ century 'age of enlightenment' makes many of us uneasy about addressing this issue. We fear mixing the scientific with the spiritual. Indeed, some see science and religion as not merely divorced from each other, but in active opposition. This has been reflected in the lack of consideration of spiritual issues and values in the training of doctors and other health professionals. Physicians and others in positions of power may also feel uneasy in case they inflict their religious beliefs (or lack of them) on their patients. Here we try to adopt an evidence-based approach to resolving these dilemmas.

\section{Definitions}

Old age is commonly seen as having several stages; the National Service framework for Older People (Department of Health 2001) describes three:

- Entering old age (can start as young as 50 years);

- Transitional phase (early retirement when health and physical capacity remain good);

- Frail old age (when increasing fragility and dependence are found).

In everyday life, successful ageing can be described as coping well with the challenges and crises of growing old. Good mental health in old age depends on the absence of specific disease processes but, perhaps even more, on how we cope with any challenges that occur. Even with such devastating diseases as severe depression or dementia, recovery or successfully coping with progressive disease depends on personal and interpersonal resources as well as specific treatments.

Religion and spirituality are related - but not identical - concepts. One definition of spirituality is 'a quality that goes beyond religious affiliation, that strives for inspiration, awe, meaning and purpose, even in those who do not believe in any God' (Murray and Zenter 1986). Religion, on the other hand, can be viewed as the 'politics' of spirituality: the rituals, beliefs and power 
structures found in different religious creeds - or more succinctly, as the means by which we relate to God.

\section{Evidence base}

Some of the most detailed work on the relationship between religious beliefs and mental health in old age has been carried out by Harold Koenig and associates at Duke University in the United States (Koenig 1994). They looked at self reports relating to how important religion was to the individual and found those for whom religion had become increasingly important with ageing were less likely to be depressed (as scored on the observer-rated Hamilton Depression Scale and the self-rated Geriatric Depression Scale). They and others working in the United States (US) found around a third of men and two-thirds of women spontaneously mentioned religion as important for coping with the challenges of old age. Major depression and depressive symptoms were less in those with a religious affiliation or self-reported high religious coping, though other variables may have influenced these results.

In other studies, strong religious affiliation was inversely related to levels of anxiety but, again, other variables may have mediated these results. Whether or not the association is directly causal it seems that, within North American culture, religious practice and coping styles are generally associated with less anxiety and depression. The evidence base is complicated. Those wishing to understand it further are referred to Koenig's excellent books (Koenig 1994, 1997). But the research in this field offers a fascinating trail of evidence. Methodologically sound research shows, for example, that over a six-year period among non-disabled elderly, lack of private religious activity (prayer) is associated with an increased risk of death (hazard ratio 1.6, 95 per cent confidence internal 1.2-2.2). Not all religious belief is positive. For example, a two-year followup of medical inpatients showed those who believed God was punishing them, had abandoned them, did not love them, did not have the power to help or felt their church had deserted them, experienced 19-28 per cent greater mortality (Pargament et al 2001).

There is relatively little quantitative research about spirituality and depression. There is even less about spirituality and dementia. A carer recently told us about two people with dementia who attended their local Salvation Army meeting and appeared to get great benefit from joining in, especially with the singing. One of the authors knew a woman with moderate dementia who attended a (largely silent) Quaker meeting for workshop and others have written about the engagement of old people, including those with dementia, in religious activity (Jewel 1986). Given the lack of ability of many older people with dementia to be able to independently attend religious services, we must question whether - in effect - depriving them of the opportunity to do so for want of an escort, can be counted as a form of abuse.

\section{Practical applications}

The process of medical consultation can be construed as involving three elements: 
- A good interpersonal relationship between doctor and patient;

- sound technical skills and knowledge; and

- a creative synthesis of knowledge and skills with the patient's situation to produce effective solutions.

Looking at these in turn, we can examine how they may interrelate with the patient's spiritual and emotional well being.

\section{Good interpersonal relationship}

Mutual respect and positive regard are the foundations for good relationships. The doctor must respect the patient as a person with their own beliefs and integrity. Patients must respect their doctors' knowledge, skills and integrity in order to place trust in their assessment and advice. This respect includes respect for different religious and spiritual beliefs and values. When working with older people it is likely (but by no means certain) that doctors, coming from a younger generation, often a different culture and a scientific background, will have different religious beliefs to their patients. Ethical standards forbid any imposition of religious values on the consultation. However, given the evidence base about usually (but not always) positive impact of religious coping, how far should doctors seek to reinforce religious beliefs where they exist? This is a relatively simple issue to address where doctor and patient share a common culture and religious affiliation, though even here care should be taken not to make too many assumptions about shared values and beliefs. Where there is a difference in religious beliefs, it may still be legitimate for the doctor to encourage patients in their own religious practices.

\section{Key points}

- Spirituality and religious practice can affect mental health.

- Spiritual beliefs can even influence mortality.

- Doctors have a duty not to impose their own beliefs on patients.

- They also have a duty to respect patients' spiritual and religious beliefs and practices, and encourage them where appropriate.

\section{Sound technical skills and knowledge}

Maintaining good medical practice is an obligation on all doctors. This means maintaining skills and staying up-to-date with the evidence base for practice. There is clearly an obligation to exercise those skills and apply that knowledge in the diagnosis and treatment of older patients. The relevant knowledge base will vary from patient to patient and from medical specialty to specialty. Part of that knowledge base now includes the emerging research about the effects of religious beliefs on health and survival. Applying that knowledge base depends on the relationship between doctor and patient discussed above. In a multicultural society, we would do well to be informed about the variety of religious beliefs and 
values held by our patients so that we can be sensitive to them in our practice. When appropriate we need to enquire of our patients about their religious beliefs and their relevance (if any) to the issues they bring to us. Most older people in the United Kingdom are currently likely to belong (at least nominally) to a Christian group, but as time goes on an increasing number will belong to other faith groups. Some of the background issues are explored, predominantly but not exclusively from a Christian point of view, in the book 'Spirituality and Ageing' (Jewel et al 1986).

\section{Co-creating solutions}

The model of medical practice has shifted from the one where patients bring their problems to doctors, who make a diagnosis and prescribe treatment. Some patients, especially older patients remain very comfortable with this model - and we should respect this, too. Some situations also lend themselves to this model. For example, the patient who has an acute illness, especially one that is life-threatening, will be only too willing for the doctor to 'take charge'. Increasingly, however, patients and doctors engage in developing a shared understanding of the problem and agreeing solutions that are appropriate and acceptable to both. As Oppenheimer writes: 'If we could do one single thing to make older people's lives happier, the best would be to stop stereotyping and treat them as individuals' (Oppenheimer 1986). And so we come full circle: the capacity to co-create solutions for patients' health problems depends upon the quality of our relationships with them and our ability to use our technical knowledge and skills in understanding their problems and agreeing with them the best way forward. Beyond that, we can also contribute to making sure that people with dementia have their spiritual needs met, perhaps by encouraging the use of Spiritual Care Plans (Moffitt and Hammond available through the Levison Centre). For more information on these care plans, how they are of benefit and how they may be implemented, there are some useful websites:

\section{Methodist Homes for the Aged: http://www.methodisthomes.org.uk}

Levison Centre (hosts the Christian Council on Ageing Dementia Group website): http://rps.gn.apc.org/leveson/resources/study-ccoa.htm

Editor's Note: this article first appeared in Geriatric Medicine in December 2006. It is reprinted with kind permission of Deborah Valentine, Editor of Geriatric Medicine. The authors would like to re-state the comment in their article that service users saw spirituality as an important resource and invite correspondence from people of different religious and cultural backgrounds. 


\section{References}

Department of Health. 2001. National Service Framework for Older People. Department of Health, London.

Helm, H., Hays, J.C., Flint, E., Koenig, H.G., Blazer, D.G. Effects of private religious activity on mortality of elderly disabled and nondisabled adults. Journal of Gerontology (Medical Sciences) 2000. 55A: M400-M405.

Jewel, A. 1986. Spirituality \& Ageing. Jessica Kingsley Publishers, London \& Philadelphia.

Koenig, H. 1994. Aging \& God. Haworth Pastoral Press, Binghamton NY.

Koenig, H. G., Hays, J.C., George, L.K., Blazer, D.G., Larson, D.B. \& Landerman, L.R. Modeling the cross-sectional relationships between religion, physical health, social support and depressive symptoms. American Journal of Geriatric Psychiatry 1997, 5:131-143.

Moffitt, L., Hammond, G. Spiritual Care: guidelines for care plans. Christian Council on Ageing Dementia Group, obtainable through the Leveson Centre.

Murray \& Zenter. 1986. In Jewel A Spirituality and Ageing. Jessica Kingsley Publishers, London \& Philadelphia.

Oppenheimer, H. 1986. In Jewel A Spirituality \& Ageing. Jessica Kingsley Publishers, London \& Philadelphia.

Pargament, K.I., Koenig, H.G., Tarakeshwar, N., \& Hahn, J. 2001. Religious struggle as a predictor of mortality among medically ill elderly patients: A two-year longitudinal study. Archives of Internal Medicine 2001. 161: 1881-1885. 